occurs might make a significant impact on the devastating morbidity and mortality of coronary artery disease, but I hope it will not be done at the expense of increasing the already widespread fear of the condition.-I am, etc.,

R. H. SALTER Cumberland Infirmary Carlisle

\section{Natural History of Ventricular Septal Defect}

SIR,-Your leading article on the natural history of ventricular septal defect (4 December 1971 , p. 571) digresses to make a welltimed and well-justified appeal for primary closure of large ventricular septal defects in infancy. However, it might be misleading to some of your readers in seeming to suggest that primary closure of ventricular septal defects in young sick infants can now be offered at a known low risk in this country. As far as I am aware no such statistics are available, and the results to which you refer from overseas relate to only small numbers of younger infants. Conceivably, also, centralization of this operation for these young and usually very sick infants might not prove practicable. At the present time it would seem that there may still be a place for advising pulmonary artery banding in selected patients. - I am, etc.

\section{K. A. HaLlidie-SMITH}

\section{Hammersmith Hospital}

London $\$ 12$ oHS

\section{Psychosis and Ketamine}

SIR,-We read with interest the report of a psychotic illness following ketamine anaesthesia (13 November, p. 428).

In February of this year a 23-year-old female was admitted to our burns unit. She had been an inpatient in a mental hospital, suffering from psychotic depression in the puerperal period after the birth of her second child. She had set her bed clothes on fire and sustained $38 \%$ deep full-thickness burns of her trunk, right upper limb, and right lower limb. She required three major operations for removal of slough and skin grafting and one minor skin grafting procedure. She also required eleven burns dressings.

The first and the second major operations were performed with conventional anaesthesia using nitrous oxide, oxygen, and halothane. Each of these anaesthetics was complicated by profound hypotension despite adequate blood replacement. It was then decided to perform subsequent skin grafting and the major dressings with ketamine anaesthesia. She had six uncomplicated ketamine anaesthetics. She was premedicated either with pethidine, promethazine, and atropine or with droperidol and atropine, and she was sedated postoperatively with diazepam or chloropromazine. The maximum dose of ketamine administered was $260 \mathrm{mg}$ during a 90-minute operation. She also had six minor burns dressings with methoxyflurane analgesia.

She never had unpleasant dreams but always complained of feeling detached from herself in the postoperative period. This feeling was less unpleasant when she was sedated with chlorpromazine. Her mental condition while in the burns unit was not upset by ketamine, and her subsequent psychiatric progress has in no way been affected by the use of ketamine.
Our experience with this patient has eminently suitable for treatment by intubashown, contrary to accepted opinions, that tion with a plastic nasotracheal tube.

ketamine can be used with its distinct The management of tracheostomy and advantages in patients who are mentally ill. endotracheal intubation is very similar-that It is necessary to use a premedication and to is, adequate humidification and routine avoid overdosage with the drug. Postopera- suction with an aseptic technique. We would tive sedation is probably advisable in these be interested to know what form of sedation, cases.-We are, etc., if any, was given to these children to enable S. M. LAIRD them to tolerate the procedure of bronchoM. SAGE scopy and tracheostomy. In conclusion, we would reinforce the suggestion that there is a need for every doctor to be aware of the existence of this condition and of the very urgent need for appropriate treatment.-We are, etc.

\section{Idiosyncratic Responses to Phenothiazines}

SIR,-We would like to report three cases in which acute extrapyramidal symptoms developed after treatment for nausea by a single dose of perphenazine. A number of points emerged. Firstly, considerable confusion in diagnosis may arise. In these cases the following diagnoses were considered: epilepsy, hysteria, tetany, and tetanus. Secondly, only a small dose of perphenazine had been given. Thirdly, intravenous benztropine methanesulphonate gave complete relief of symptoms.

The signs and symptoms of idiosyncratic responses to phenothiazine drugs often cause confusion in diagnosis, for two reasons. Firstly, they are not commonly found as an acute phenomenon. Secondly, in the acute situation the symptoms produced mimic extremely well other serious conditions. Phenothiazine derivatives are well known to cause extrapyramidal symptoms when used over a long period,' but there are few reports of an acute episode. R. B. Bradshaw described a case in which symptoms occurred after a single dose. ${ }^{2}$ Diazepam may help to control the spasms but benztropine methanesulphonate has been shown to be a specific antidote.

We would like to emphasize this bizarre side effect of the phenothiazine group of drugs, and in particular of perphenazine, since it is commonly used as an antiemetic. -We are, etc.,

P. D. RAMSDEN

Nuffield Department of Surgery,

D. L. FroggatT

Nuffield Departmen

1 Ayd, F. J., foumal of the American Medical 2 Association, 175, 1054.
Otology, 1969, 83, 79.

\section{Haemophilus Epiglottitis}

SIR,-We were interested to read about the experiences of Dr. M. G. Addy and others in their paper on Haemophilus epiglottitis (1 January, p. 40). We reinforce the authors' emphasis on the fulminating nature of the condition and the need for urgent relief of the respiratory obstruction. However, we cannot agree that there is a need for tracheostomy in all cases. If the larynx can be visualized-and this procedure must be carried out in an area where emergency tracheostomy could be performed-then it is as easy to introduce an endotracheal tube as
it is a bronchoscope. Failure of intubation in this condition is a possibility but is rare in our experience. Since antibiotic therapy is rapidly effective if administered parenterally, the artificial airway is needed only for 4872 hours, and it seems to us a condition
The Children's Hospital,

JENNIFER M. EDWARDS KEITH D. ROBERTS

\section{Ladywood,}

SIR,-We are most interested to read the article on haemophilus epiglottitis by $D r$. M. G. Addy and others (1 January, p. 40), and we would like to reinforce further their statement that the disease is not merely a local inflammation but also a septicaemic condition by describing our recent clinical experience with a child admitted to this hospital with "croup."

A 16-month-old boy was admitted with a history of being unwell for a day and noisy distressed respirations for two hours before admission. On admission he looked ill and ashen with a moderate laryngeal stridor. His emperature was $39.8^{\circ} \mathrm{C}$ and the respirations were 40 a minute with a moderate subcostal recession. He had inspiratory wheeze with scattered crepitations over the right base. The pulse rate was 156 , regular with good volume, and there were no signs of cardiac failure. There was no evidence of meningitis and no other abnormal signs. The $\mathrm{Hb}$ was $13.2 \mathrm{~g} / 100$ $\mathrm{ml}$, E.S.R. $45 \mathrm{~mm}$ in one hour, and W.B.C. $15,400 / \mathrm{mm}^{3}$ with polymorphs $60 \%$, lymphocytes $35 \%$, monocytes $3 \%$, and eosinophils $2 \%$.

The child was treated, as having acute laryngitis, in an oxygen tent with an adequate humidification under cover of ampicillin, cloxacillin, and hydrocortisone. The antibiotics were given six-hourly in doses of $125 \mathrm{mg}$ intramuscularly for two days and then given orally. The patient was afebrile on the second day and out of the tent on the third. He remained so until the fifth day when he became irritable and pyrexial with a few meningeal signs. A lumbar puncture produced a slightly cloudy fluid with leucocytes $810 / \mathrm{mm}^{3}$ (polymorphs $33 \%$, mononuclears $67 \%$ ) sugar $53 \mathrm{mg} / 100 \mathrm{ml}$, protein 140 $\mathrm{mg} / 100 \mathrm{ml}$, and a growth of Haemophlus influenzae type $b$ was obtained. The treatment of the meningitis was begun on the same day with chloramphenicol, sulphadimidine, and penicillin in the standard doses. He responded to the treatment quite satisfactorily and is fully recovered now.

The points we would like to make from this case are that any child with a moderate to severe croup should be treated as for Haemophilus influenzae type $b$ infection with adequate doses of parenteral ampicillin or chloramphenicol. Ampicillin, if used, should be given in maximum doses (100$150 \mathrm{mg} / \mathrm{kg} / \mathrm{day}$ ) and parenterally. Once the blood culture becomes positive for Haemophilus infuenzae type $b$ it is important to change over to chloramphenicol to avoid meningitis.-We are, etc.,

B. WOLMAN

P. M. M. REDDY

Booth Hall Children's Hospital,

L. N. MuRtaza 